\title{
Detection of Gliadin in Foods Using a Quartz Crystal Microbalance Biosensor That Incorporates Gold Nanoparticles
}

\author{
Pei-Tzu Chu, ${ }^{\dagger}$ Chih-Sheng Lin, ${ }^{\S}$ Wei-Jung Chen, ${ }^{\otimes}$ Chih-Feng Chen, ${ }^{\ddagger}$ and Hsiao-Wei Wen ${ }^{*}{ }^{\dagger}$ \\ ${ }^{\dagger}$ Department of Food Science and Biotechnology, National Chung Hsing University, Taichung, Taiwan, Republic of China \\ ${ }^{\S}$ Department of Biological Science and Technology, National Chiao Tung University, Hsinchu, Taiwan, Republic of China \\ ${ }^{\otimes}$ Institute of Biotechnology, National I-Lan University, I-Lan, Taiwan, Republic of China \\ ${ }^{\ddagger}$ Department of Animal Science, National Chung Hsing University, Taichung, Taiwan, Republic of China
}

ABSTRACT: This work develops a label-free gliadin immunosensor that is based on changes in the frequency of a quartz crystal microbalance (QCM) chip. A higher sensitivity was obtained by applying $25 \mathrm{~nm}$ gold nanoparticles (AuNPs) to the surface of a bare QCM electrode. Subsequently, chicken anti-gliadin antibodies (IgY) were immobilized directly on the AuNP-modified surface by cross-linking amine groups in IgY with glutaraldehyde. Experimental results revealed that the change in frequency exhibited when $2 \mathrm{ppm}$ gliadin was bound to the AuNP-modified electrode was $35 \mathrm{~Hz}(48 \%)$ greater than that of the bare gold electrode. The linear dynamic range in $60 \%$ ethanol was from $1 \times 10^{1}$ to $2 \times 10^{5} \mathrm{ppb}$ gliadin, and the calculated limit of detection (LOD) was $8 \mathrm{ppb}$. The entire detection process was completed in $40 \mathrm{~min}$ and was highly repeatable. Additionally, the AuNPmodified QCM system generated results in the detection of gliadin in 10 commercial food products that were consistent with those obtained using an AOAC-approved gliadin kit. In conclusion, the QCM platform provides a potential alternative means of ensuring that people with wheat allergies and celiac patients have access to gliadin-free food.

KEYWORDS: gliadin, quartz crystal microbalance immunosensor, gold nanoparticles

\section{INTRODUCTION}

Cereals and cereal products are important food resources for human beings. As well as serving as a major energy source, owing to their high carbohydrate content, cereals are also vital sources of vitamins, minerals, soluble and insoluble dietary fibers, and proteins. Of all of the cereals, wheat is not only a particularly important cultivated crop but also an allergenic food. In the United States, wheat-related food allergies constitute approximately $2.5 \%$ of all food allergies in children. ${ }^{1}$ In France, wheat ranks as the 8th most common food allergen in children and the 12th most common in adults; $14-20 \%$ of the entire French population with a food allergy is allergic to wheat. ${ }^{2,3}$ Although rice is a staple food in Asia, wheat products such as noodles and bread are still widely consumed. Consequently, wheat is also responsible for a significant proportion of food allergies in Asia. Following eggs and dairy milk, wheat ranks as the third food allergen in Japan. ${ }^{4}$ In eastern Taiwan, wheat allergies constitute around $5.4 \%$ of all food allergies in children.

Wheat gluten is composed of many alcohol-soluble proteins, of which the main one is gliadin. ${ }^{6}$ Gliadin is a major allergen that is responsible for gluten intolerance, bakers' asthma, and wheat-dependent exercise-induced anaphylaxis. ${ }^{7}$ Celiac disease (CD) is a genetically determined autoimmune disease of the digestive system, which results in chronic inflammation of the gastrointestinal tract. ${ }^{8} \mathrm{CD}$ flattens the small intestinal mucosa, hindering nutrient absorption. The condition can be reversed by a gluten-free diet. ${ }^{9}$ Previous studies have demonstrated that the safe limit on ingested wheat protein is higher for wheatallergic patients than for celiac patients. ${ }^{10}$ Because the sensitivity to gluten varies among individuals, it is not easy to set an acceptable limit on trace amounts of gluten in gluten-free foods. ${ }^{11}$ Recently, the official limit set by regulation (EC) No. $41 / 2009$ of the European Union for all foodstuffs except infant formulas is currently $<20 \mathrm{mg} / \mathrm{kg}$ of gluten in gluten-free foods and $20-100 \mathrm{mg} / \mathrm{kg}$ of gluten in very low-gluten content food. ${ }^{12}$ Therefore, highly sensitive assays are crucial for detecting gluten contaminants in gluten-free food.

Numerous methods for detecting wheat allergens have been established. They are mass spectrometry, ${ }^{13}$ the polymerase chain reaction (PCR) ${ }^{14}$ real-time PCR, ${ }^{15}$ and immunological tests. ${ }^{16-18}$ For example, a biosensor that is based on a fluorescence assay was used to detect the amino acid sequence XXQPQPQQQQQQRQQQQQL, which is represented in gliadin and other prolamins and is considered to be toxic to celiac patients. This sensor exhibited a linear response between 2.0 and $8.0 \mu \mathrm{M}$ gliadin. ${ }^{19}$ An electronic tongue has previously been developed for the semiquantitative detection of gliadin with a sensitivity of $1-2 \mathrm{mg} / \mathrm{kg}$ of gliadin in baby milked flour. ${ }^{20}$ However, a standard quantitative method is required to determine the gluten concentration in food. Two officially approved enzyme-linked immunosorbent assay (ELISA) kits have been developed to quantify native and heated gluten. The first commercial kit, approved by the Association of Official Analytical Chemistry (AOAC), uses a monoclonal antibody to detect $\omega$-gliadin, whereas the second one, approved by the Codex Alimentarius Commission, utilizes an R5 monoclonal

Received: November 21, 2011

Revised: $\quad$ May 25, 2012

Accepted: June 14, 2012

Published: June 14, 2012 
antibody to react with the celiac toxic epitope of gliadin, QQPFP. ${ }^{21}$ However, these gliadin analysis systems are timeintensive, inconvenient, and expensive and require that their operators have been extensively trained. Therefore, a rapid, sensitive, user-friendly, and environmentally friendly analytical system must be developed for detecting gliadin in foods.

Some label-free methods, including surface plasmon resonance (SPR) and quartz crystal microbalance (QCM), have been developed. ${ }^{22}$ In 1959, Sauerbrey established the relationship between the change in resonant frequency of quartz and the change in mass of attached molecules on the surface of a gold electrode in a QCM, leading to the development of QCM as a commonly used biosensor that depends on the increase in mass that is caused by the absorption of target molecules. ${ }^{23,24}$ As a directly responsive microsensor, QCM is extensively applied in the liquid phase because it supports rapid analysis and free labeling, is relatively easy to use, and exhibits both high selectivity and high sensitivity. Therefore, QCM has been used as an immunosensor in clinical diagnosis, ${ }^{25}$ food toxin analysis, ${ }^{26}$ microorganism pollution detection, ${ }^{27,28}$ environmental protection, ${ }^{29}$ and agricultural monitoring. ${ }^{30}$

Recently, fundamental studies and technological applications have exploited biosensing assays that are based on gold nanoparticles (AuNPs) because they are low-cost, provide a high surface area, and are easy to process. ${ }^{31,32}$ Some novel analytical methods that use AuNPs have been found to have a better detection limit. For example, the QCM DNA sensing system uses AuNPs as carriers and is adopted in the investigation of DNA hybridization, ${ }^{33}$ and layer-by-layer AuNP hybridization has been used to detect the dengue virus. ${ }^{34}$ The objective of this work is to increase the number of anti-gliadin antibody binding sites and the subsequent target mass on a QCM chip by modifying the surface of the gold electrode in the QCM with AuNPs. The changes in frequency $(\Delta F)$ and assay sensitivity of this developed QCM were compared with those of the traditional QCM with an unmodified gold electrode.

\section{MATERIALS AND METHODS}

Materials. Wheat, barley, oat, rice, foxtail millet, corn, buckwheat, and soybean were purchased from local supermarkets (Taichung, Taiwan). Wheat gliadin, hydrogen tetrachloroaurate (III) trihydrate, sodium citrate, glutaraldehyde, cysteamine, glycine, polyethylene glycol 10000 (PEG10), and other chemicals were purchased from SigmaAldrich Co. (St. Louis, MO, USA). A QCM sensor, $9 \mathrm{MHz}$ AT-cut piezoelectric quartz crystal chips with gold electrodes (each side of which has an area of $0.091 \mathrm{~cm}^{2}$ ) that were modified with $\mathrm{NH}_{2}$ functional groups, and the flow injection applicator were all purchased from ANT Technology Co., Ltd. (Taipei, Taiwan). A RIDASCREEN Gliadin kit was purchased from R-Biopharm AG (Darmstadt, Germany).

Preparation of Wheat Protein Sample. Wheat protein was extracted using two methods. The first was ethanol extraction, and the other involved the RIDA extraction buffer by following the manufacturer's instructions. In the ethanol extraction method, wheat flour $(1 \mathrm{~g})$ was rotatively mixed with $10 \mathrm{~mL}$ of reverse osmosis water (RO) for $1 \mathrm{~h}$ at room temperature. After centrifugation at $5000 \mathrm{rpm}$ for $10 \mathrm{~min}$, the pellet was formed and was extracted with $10 \mathrm{~mL}$ of $60 \%$ ethanol for $1 \mathrm{~h}$ to obtain gliadin. In the second method, the RIDA extraction solution $(2.5 \mathrm{~mL})$ in the RIDASCREEN Gliadin kit (RBiopharm AG) was added to $0.25 \mathrm{~g}$ of wheat flour and mixed for 40 min at $50{ }^{\circ} \mathrm{C}$, and this mixture was then reacted with $7.5 \mathrm{~mL}$ of $80 \%$ $(\mathrm{v} / \mathrm{v})$ ethanol for $1 \mathrm{~h}$ at room temperature. The mixture was centrifuged at $5000 \mathrm{rpm}$ for $10 \mathrm{~min}$ at room temperature to collect the supernatant that contained the extracted gliadin. Additionally, a commercially bought gliadin (Sigma-Aldrich Co.) was used to prepare a standard gliadin solution.

Immunization of Hens. The white Leghorn hen lays eggs continually throughout the year, approximately $280 \mathrm{egg} /$ year, and so was adopted herein to obtain egg yolk immunoglobulin (IgY). Hens were immunized following the procedure of Kim et al. ${ }^{35}$ Eight 40 week-old white Leghorn hens were kept in standard facilities for poultry farming and provided with food and water. To investigate the preimmuno background, eggs were collected before the first injection. The Leghorn chicken was vaccinated in the thorax muscle at two sites using $1.5 \mathrm{~mL}$ of gliadin-complete Freund's adjuvant mixture. The antigen mixture that was used in the first injection was prepared by mixing $0.5 \mathrm{~mL}$ of the gliadin standard solution $(1 \mathrm{mg} / \mathrm{mL})$ with $1 \mathrm{~mL}$ of the complete Freund's adjuvant. After 14 days, a second boost injection was given. In the second injection, incomplete Freund's adjuvant replaced complete Freund's adjuvant. Eggs were collected daily throughout the immunization period until 1 week after the third boost, and each was stored at $4{ }^{\circ} \mathrm{C}$ until use.

Preparation of Anti-gliadin IgY from Yolk. Anti-gliadin IgY was isolated from gliadin-immunized chicken eggs using three methods, which were the chloroform-PEG method, ${ }^{36}$ the PEG-alcohol (PEGAlc) method, ${ }^{37}$ and the water dilution method. ${ }^{38}$ The PEG-Alc method is explained briefly herein because this study mainly used this method to isolate IgY from eggs. First, the egg yolk was washed gently with clean water to remove as much egg white as much as possible. A volume of $3.5 \%$ PEG10 in $0.1 \mathrm{M}$ phosphate buffer saline (PBS, $\mathrm{pH}$ 7.6) that was 4 times the volume of the egg yolk was mixed with the yolk. Following stirring, the mixture was centrifuged at $8000 \mathrm{rpm}$ for $10 \mathrm{~min}$, and more PEG10 was added to the clear supernatant to obtain a final concentration of $12 \%(\mathrm{w} / \mathrm{v})$. After the mixture had been centrifuged at $8000 \mathrm{rpm}$ for an additional $10 \mathrm{~min}$, the supernatant was removed and the pellet was dissolved in a PBS equivalent to half of the volume of the original yolk/PBS mixture. PEG10 was then added to a final concentration of $12 \%(\mathrm{w} / \mathrm{v})$. The mixture was centrifuged again at $8000 \mathrm{rpm}$ for $10 \mathrm{~min}$, and the supernatant was removed. The pellet was then dissolved in PBS and 50\% ethanol with a total volume of half of the original volume of the yolk. Next, the extract was centrifuged, and the pellet was dissolved in $1 \mathrm{~mL}$ of PBS before being dialyzed against PBS for $24 \mathrm{~h}$. Finally, the concentration, titer, and purity of IgY were estimated with protein assay (at $280 \mathrm{~nm}$ ), ELISA, and Western blot analysis, respectively.

Preparation of AuNPs. The solution of AuNPs was obtained by the reduction of $\mathrm{HAuCl}_{4}$ using citrate, as described by Saraiva et al. ${ }^{39}$ Fifteen milliliters of deionized water was added to $10 \mathrm{~mL}$ of $0.1 \%$ $\mathrm{HAuCl}_{4}$ in an oil bath. After the temperature had reached $120{ }^{\circ} \mathrm{C}$, a volume $(3.06,2.42$, or $0.88 \mathrm{~mL}$ ) of $38.8 \mathrm{mM}$ sodium citrate was rapidly added to yield differently sized AuNPs. A color change from dark blue to wine-red revealed the formation of AuNPs. Next, the size of the AuNPs was measured by laser diffraction particle size analysis in a light-scattering particle size analyzer (Coulter Scientific Instruments, Hialeah, FL, USA). Finally, the AuNPs were stored at $4{ }^{\circ} \mathrm{C}$ until use.

Optimization of QCM Biosensor. The QCM biosensor was optimized by applying various concentrations $(100,200$, or $300 \mu \mathrm{g} /$ $\mathrm{mL}$ ) of polyclonal anti-gliadin IgY onto the AuNP-modified chip at various flow rates $(5,10,20$, or $60 \mu \mathrm{L} / \mathrm{min})$ through the QCM chips. The flow rate was controlled by the flow injection system, and the entire QCM system was purchased from ANT Technology Co., Ltd. (Taipei, Taiwan). Two methods for immobilizing IgY on the surface of the gold electrode are (i) the direct immobilization of IgY onto the electrode and (ii) the indirect immobilization of $\operatorname{IgY}$ onto the electrode via the immobilization of AuNPs. Herein, method i involved directly fixing the anti-gliadin IgY onto the gold electrode surface with glutaraldehyde and then blocking with $1 \mathrm{M}$ glycine. In method ii, the electrode was first coated with AuNPs by using glutaraldehyde and cysteamine as linkers. Following the immobilization of AuNPs on the electrode, $0.5 \mathrm{M}$ cysteamine was again injected to form the $\mathrm{NH}_{2}$ groups on the AuNP surface. The anti-gliadin IgY was then attached to the surface of AuNPs using $2.5 \mathrm{M}$ glutaraldehyde. Between each step of the immobilization process, the electrode surface was washed until a 
Scheme 1. Production of the AuNP-Modified Electrode of QCM by Adding (a) 2.5 M Glutaraldehyde, (b) 0.5 M Cysteamine, (c) AuNPs, (d) 0.5 M Cysteamine, (e) 2.5 M Glutaraldehyde, (f) Anti-gliadin IgY, and (g) 1 M Glycine
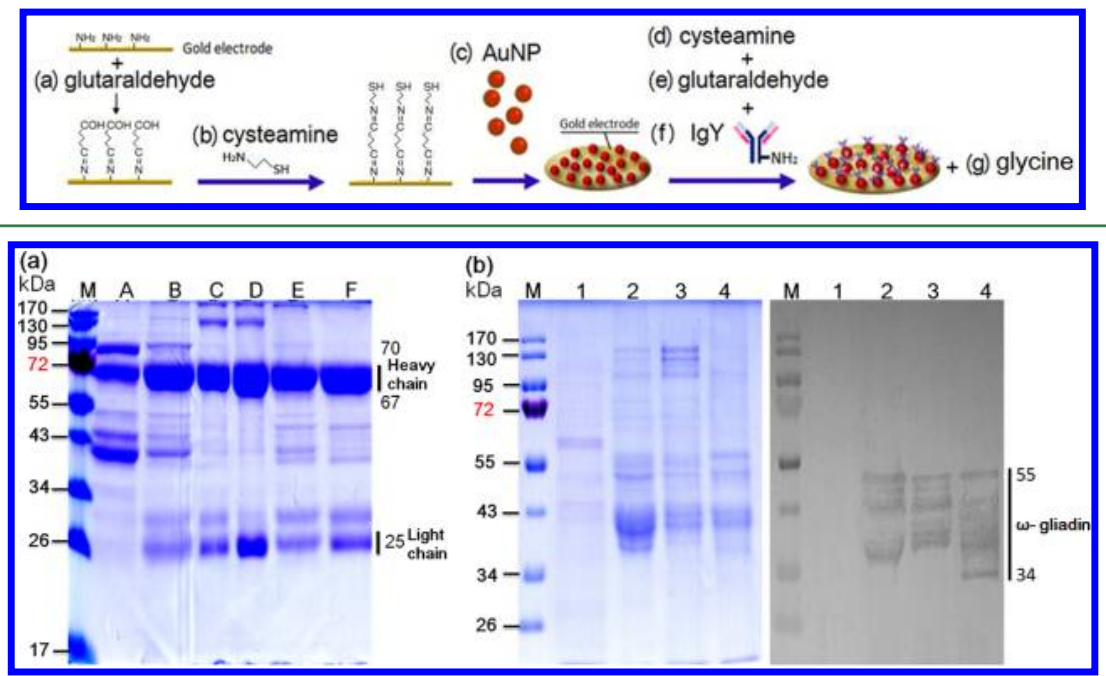

Figure 1. (a) Consequence of electrophoretic separation on SDS-PAGE (12\%) of anti-gliadin IgY antibody. Lanes: M, molecular weight markers; A and $\mathrm{B}$, chloroform-PEG method; $\mathrm{C}$ and $\mathrm{D}, \mathrm{PEG}-\mathrm{Alc}$ method; $\mathrm{E}$ and $\mathrm{F}$, water dilution method. Molecular weight of chicken IgY of each heavy chain is $67-70 \mathrm{kDa}$, and each light chain is $25 \mathrm{kDa}$. (b) Electrophoretic separation of wheat proteins on SDS-PAGE (left) and the subsequent result of Western blot with chicken anti-gliadin IgY antibody (right). Lanes: 1, albumins from wheat; 2, wheat gliadin extracted using 60\% ethanol; 3, wheat gliadin extracted using RIDA extraction solution; 4, standard gliadin from Sigma-Aldrich Co. Chicken anti-gliadin IgY antibody specifically bound to $\omega$-gliadin and did not recognize albumins on PVDF membrane.

constant frequency was obtained. Scheme 1 illustrates each step of the surface modification of the QCM gold electrode using method ii. Distilled water $(18.2 \mathrm{M} \Omega \mathrm{cm}$ ) was used as the running buffer, and the change in frequency was determined using the developed QCM system.

Assay Procedure. The specificity of this developed QCM assay was using alcohol-soluble proteins (prolamins) that were extracted from various cereal samples (wheat, barley, oat, rice, foxtail millet, corn, buckwheat, and soybean). All cereals were milled to produce flour, and impurities were removed by sifting through a 100 mesh screen. The albumins and the globulins in $5 \mathrm{~g}$ of cereal flour were removed using deionized water and $0.5 \mathrm{M} \mathrm{NaCl}$ solution, respectively. Following the extraction of the pellet with $60 \%(\mathrm{v} / \mathrm{v})$ ethanol, the supernatant was filtered through a $0.45 \mu \mathrm{m}$ pore sized filter. The standard gliadin from wheat was diluted with $60 \%$ ethanol serially at concentrations from $1 \times 10^{1}$ to $2 \times 10^{5} \mathrm{ppb}(\mathrm{ng} / \mathrm{mL})$ to obtain an optimized standard curve. The repeatability of the QCM assay was ensured by performing the experiment using different chips at three concentrations of gliadin (10, 100, and $1000 \mathrm{ppm})$. Moreover, to confirm the feasibility of this developed QCM assay in detecting gliadin in real food samples, it was applied to analyze 10 commercial food products, including 4 gluten-free foods (pancake mix, custard mix, baby rice, and buckwheat). The results were compared with those obtained using a RIDASCREEN Gliadin kit, which is approved by the AOAC. These four products that were certified gluten-free were guaranteed safe for celiac patients by the Spanish Federation of Celiac Associations.

Statistical Analysis. All data obtained using the developed QCM assay are presented as the mean \pm standard deviation (SD). Statistical analyses were performed with the use of the SAS statistical package (SAS Institute, Cary, NC, USA). A $p$ value under 0.05 was considered to indicate significance.

\section{RESULTS AND DISCUSSION}

Preparation and Characterization of Anti-gliadin IgY. To extract a large amount of chicken IgY antibody from egg yolk, three purification methods were adopted in this study. They were the chloroform-PEG method, the PEG-Alc method, and the water dilution method. ${ }^{36-38}$ Figure 1a presents the variety of purified egg proteins that were analyzed using the $12 \%$ SDS-PAGE. In lanes A, C, and E were the egg proteins from the control egg that were collected before immunization, and in lanes $\mathrm{B}, \mathrm{D}$, and $\mathrm{F}$ were the egg proteins after the first boost. The results from lanes B, D, and F reveal a higher concentration of $\operatorname{IgY}$ than in the corresponding control eggs (lanes A, C, and E). The chloroform-PEG method (lanes $\mathrm{A}$ and $\mathrm{B}$ ) and the water dilution method (lanes $\mathrm{E}$ and $\mathrm{F}$ ) very effectively extracted the antibody IgY from the yolk, and the PEG-Alc method (lanes C and D) yielded clear bands for the heavy chain and the light chain of IgY antibodies with the correct molecular weights. Hence, the PEG-Alc method was chosen as the optimal method for isolating IgY from egg yolk. The purified antibodies from the egg yolks of the eggs collected before immunolization $(n=3)$ were $34 \pm 2 \mathrm{IgY} \mathrm{mg} / \mathrm{mL}$. The first boost increased the antibody concentration to $90 \pm 13$ $\mathrm{mg} / \mathrm{mL}$, and the second boost increased it to $188 \pm 10 \mathrm{mg} / \mathrm{mL}$. Additionally, Figure $1 \mathrm{~b}$ displays the profiles of wheat proteins that were extracted through various methods and the Western blot images with the use of isolated anti-gliadin IgY through the PEG-Alc method. In lane 1 were water-soluble wheat proteins; in lanes 2 and 3 were ethanol-soluble wheat proteins obtained by different extraction methods (lane 2, 60\% ethanol; lane 3, RIDA extraction solution), and in lane 4 was the gliadin standard from Sigma-Aldrich Co. Wheat gliadin molecules can be divided into a high molecular weight (HMW) group (67-88 $\mathrm{kDa}$ ), a medium molecular weight (MMW) group, which includes $\omega$-gliadin proteins $(34-55 \mathrm{kDa})$, and a low molecular weight (LMW) group, which includes $\alpha / \beta$ - and $\gamma$-gliadins (28$39 \mathrm{kDa}) .^{40}$ Sixty percent ethanol (lane 2 ) could extract a higher amount of $\omega$-gliadin than RIDA extraction solution (lane 3 ). The isolated anti-gliadin IgY recognized only $\omega$-gliadin in lanes 2-4 and did not react with any of the water-soluble wheat proteins in lane 1. Accordingly, the isolated anti-gliadin IgY antibody in this work could specifically distinguish $\omega$-gliadin from other proteins in wheat. 
Immobilization of IgY on QCM Surface with AuNPs. Nanostructure possesses a high surface-to-volume ratio, and this unique property can provide a nanoparticle-modified electrode a chance to coat a larger amount of antibodies and then give the coated antibodies three-dimenational direactions to increase the likelihood of antibody-antigen interaction. These favorable properties increase the sensitivity of an immunoassay. ${ }^{41}$ Therefore, to increase the sensitivity of the QCM in the detection of gliadin, a novel immobilization method for increasing the number of IgY binding sites on a QCM chip using AuNPs, shown as Scheme 1, is developed herein. As the molar ratio of sodium citrate $/ \mathrm{HAuCl}_{4}$ decreased, larger AuNPs were obtained. When a mixture of $15 \mathrm{mLof}$ deionized water and $10 \mathrm{~mL}$ of $0.1 \% \mathrm{HAuCl}_{4}$ was added to different volumes of $38.8 \mathrm{mM}$ sodium citrate $(3.06,2.42$, or $0.88 \mathrm{~mL}$ ), AuNPs were formed with sizes of 17,25 , or $40 \mathrm{~nm}$, respectively (data not shown). Figure $2 \mathrm{~A}$ summarizes the

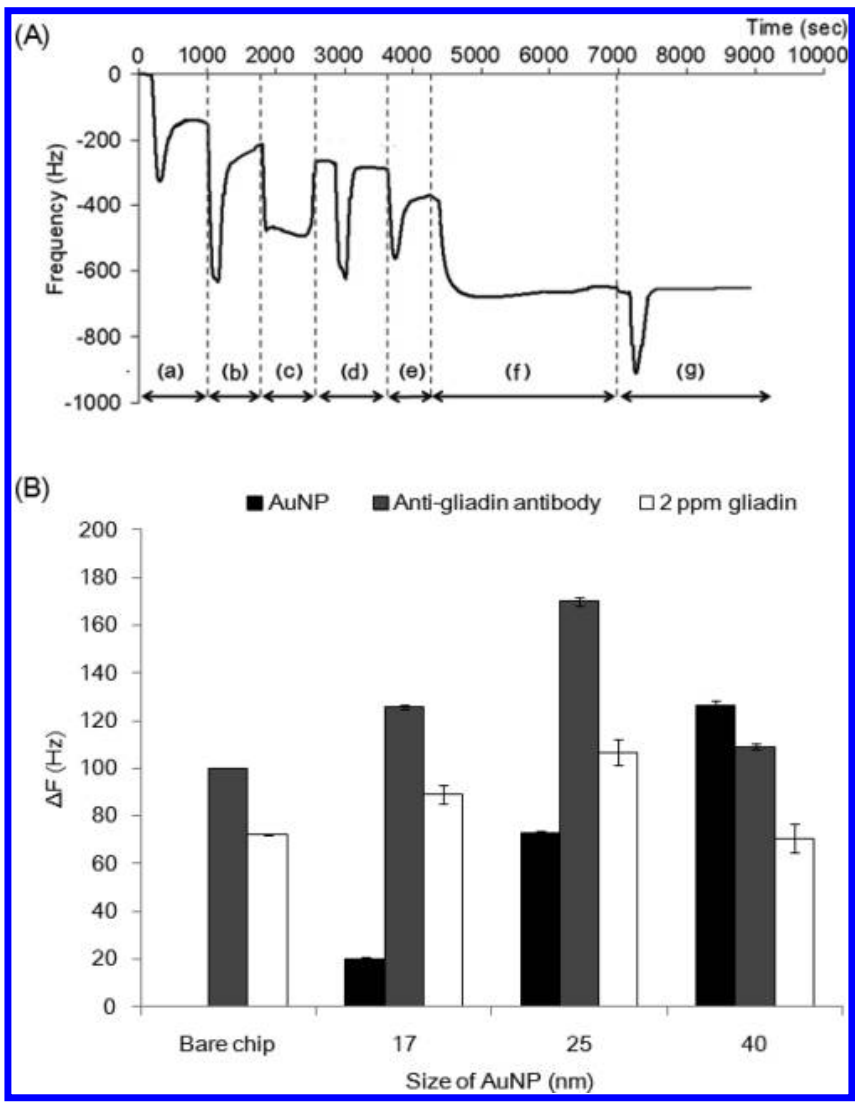

Figure 2. (A) Frequency of AuNP-modified chip throughout the modification process, measured using QCM. Modification was conducted on the gold electrode of a QCM by adding reagents (a$\mathrm{g}$ ), which were $2.5 \mathrm{M}$ glutaraldehyde, $0.5 \mathrm{M}$ cysteamine, AuNPs, $0.5 \mathrm{M}$ cysteamine, $2.5 \mathrm{M}$ glutaraldehyde, anti-gliadin IgY, and $1 \mathrm{M}$ glycine. (B) Effect of different surface modifications (with 17,25 , and $40 \mathrm{~nm}$ AuNPs/without AuNPs) on change in frequency when $\operatorname{IgY}$ was immobilized on the surface of a QCM chip.

results of the assay processing. Each arrow indicates the attachment of a different material to the surface of the QCM. Initially, in stage a, $2.5 \mathrm{M}$ glutaraldehyde was added and the carbonyl groups of glutaraldehyde interacted with the amino groups on the chip by a cross-linking reaction. Then, in stage b, the carbonyl group on the chip reacted with the cysteamine. ${ }^{42}$ In stage $c$, the AuNPs were added and interacted with the sulfhydryl group of the bound cysteamine. The consequent increase in mass yielded a $\Delta F$ around $300 \mathrm{~Hz}$, and a signal with a steady frequency was thus achieved. Following a series of chemical modifications on the AuNPs (stages $d$ and e), the anti-gliadin antibody was attached to the AuNPs in stage f. A steady interaction thus occurred between the amino groups of the antibodies and the carboxyl groups on the AuNP-modified chip, and the frequency was reduced again to approximately $680 \mathrm{~Hz}$. Finally, the vacant, active sites on the chip were blocked using $1 \mathrm{M}$ glycine.

Figure $2 \mathrm{~B}$ displays the effect of AuNP size on the binding quantity of antibodies and the assay signal as detecting $2 \mathrm{ppm}$ gliadin. Generally, $\Delta F$ increased with the size of AuNPs that coated the chip. Relative to the bare and AuNP-modified chips, coating antibody on the 17, 25, and $40 \mathrm{~nm}$ AuNP chips changed the frequency by $120 \pm 2,170 \pm 6$, and $109 \pm 3 \mathrm{~Hz}$, respectively. The decrease in the frequency of the $40 \mathrm{~nm}$ AuNP modified chip may have been caused by the aggregation of 40 $\mathrm{nm}$ AuNPs on the chip when the flow rate of the injection system was $10 \mu \mathrm{L} / \mathrm{min}$. Therefore, the coating of $25 \mathrm{~nm}$ AuNPs onto the chip was optimal, and the signal $(\Delta F)$ was $106 \pm 5 \mathrm{~Hz}$ in the detection of $2 \mathrm{ppm}$ gliadin. Compared with the bare gold electrode, the increase in frequency when $2 \mathrm{ppm}$ gliadin was detected using the $25 \mathrm{~nm}$ AuNP-modified electrode was $35 \mathrm{~Hz}$ (48\%). The SEM results demonstrate that all of the AuNPs that coated the surface of the QCM chip had similar sizes around 25 $\mathrm{nm}$, with the aggregation of a few AuNPs (Figure 3).

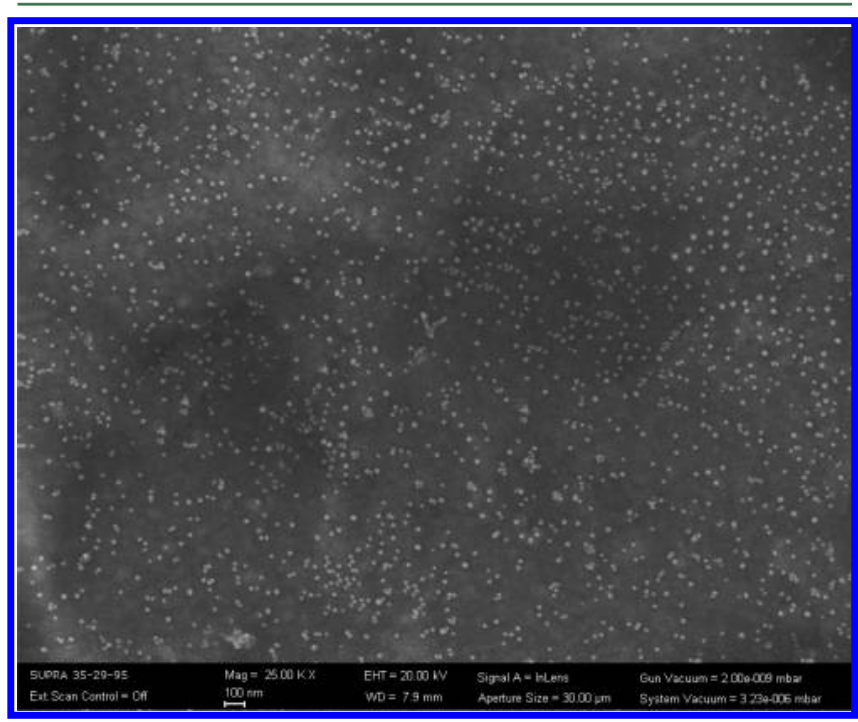

Figure 3. Phase-contrast SEM image of surface of electrode in QCM modified with $25 \mathrm{~nm}$ AuNPs.

Table 1 presents the change in frequency, the corresponding change in mass, and surface coverage by various molecules upon the modification of the bare gold electrode or the AuNPmodified electrode of the QCM. The corresponding change in mass was calculated using the Sauerbrey equation, ${ }^{23}$

$$
\Delta F=\frac{-2 \Delta m f^{2}}{\mathrm{~A} \sqrt{\mu \rho_{\mathrm{q}}}}=-C_{f} \Delta \mathrm{m}
$$

where $\Delta F=$ change in resonant frequency of the crystal $(\mathrm{Hz})$, $\Delta m=$ change in mass ( $\mathrm{ng}), f=$ intrinsic crystal frequency (9 $\mathrm{MHz}), A=$ piezo-electrically active area $\left(0.091 \mathrm{~cm}^{2}\right), \rho_{\mathrm{q}}=$ density of quartz $\left(2.65 \mathrm{~g} / \mathrm{cm}^{3}\right)$, and $\mu=$ shear modulus of 
Table 1. Changes of Parameters in Each Step of Modification of QCM Chip

$\begin{array}{llccc}\text { modification step } & \text { MW }(\mathrm{g} / \mathrm{mol}) & \text { frequency change }(\Delta F ; \mathrm{Hz}) & \text { mass change }(\Delta m ; \mathrm{ng}) & \text { surface coverage }\left(\Gamma ; \mathrm{mol} / \mathrm{cm}^{2}\right) \\ \text { bare electrode } & & & & \\ \text { (a) } 2.5 \text { M glutaradehyde } & 100.12 & 148.1 \pm 2.3 & 52.7 \pm 0.8 & 8.1 \times 10^{-9} \\ \text { (b) anti-gliadin IgY } & 180000 & 103.5 \pm 4.9 & 10.1 \pm 1.2 & 3.1 \times 10^{-12} \\ \text { (c) } 1 \text { M glycine } & 75.07 & 20.1 \pm 3.5 & 23.5 \pm 0.1 & -^{a} \times 10^{-9} \\ \text { (d) } 20 \text { ppm gliadin } & 55-39 & 72.1 \pm 0.2 & & 89.2 \pm 3.1 \\ \text { AuNP-modified electrode } & & & 44.1 \pm 1.7 & 5.7 \times 10^{-9} \\ \text { (a) } 2.5 \text { M glutaradehyde } & 100.12 & 149.3 \pm 5.6 & 37.5 \pm 2.7 & -{ }^{b} \\ \text { (b) } 0.5 \text { M cysteamine } & 77.15 & 88.7 \pm 4.7 & 32.5 \pm 2.2 & 4.6 \times 10^{-9} \\ \text { (c) AuNP } & -b & 75.4 \pm 7.7 & 40.5 \pm 1.7 & 4.4 \times 10^{-9} \\ \text { (d) } 0.5 \text { M cysteamine } & 77.15 & 65.5 \pm 6.3 & 88.6 \pm 3.3 & 5.4 \times 10^{-12} \\ \text { (e) } 2.5 \text { M glutaraldehyde } & 100.12 & 81.4 \pm 4.8 & 22.5 \pm 2.2 & 3.3 \times 10^{-9} \\ \text { (f) anti-gliadin IgY } & 180000 & 178.7 \pm 9.4 & 36.1 \pm 2.7 & -{ }^{a}\end{array}$

${ }^{a}$ Not available; gliadin was the complex as the ethanol-soluble wheat proteins with the molecular weight range as $39-55 \mathrm{kDa}$, resulting in the impossibility to calculate its surface coverage. ${ }^{b}$ Not available; the gold nanoparticle (AuNP) was the polymer for which a molecular weight was not available, resulting in the impossibility to calculate the surface coverage of AuNP.

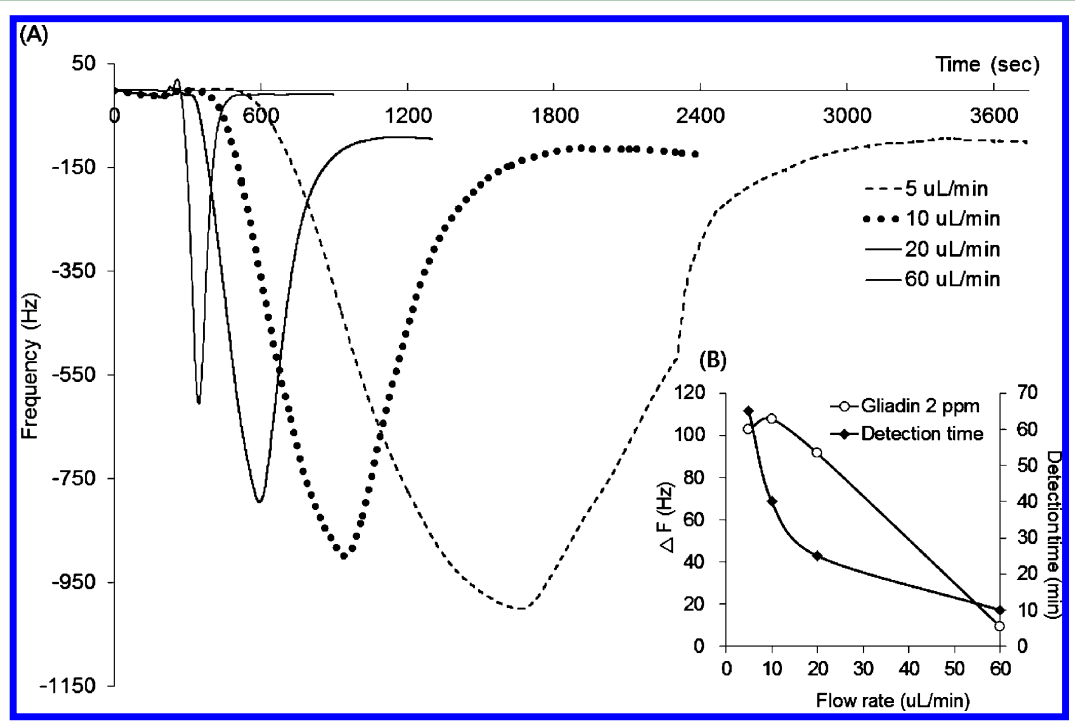

Figure 4. Effect of flow rate $(5,10,20$, and $60 \mu \mathrm{L} / \mathrm{min})$ on changes in frequency (A) and detection time (B) in detection of 2 ppm of gliadin using the developed QCM biosensor.

quartz $\left(2.95 \times 10^{11} \mathrm{dyn} / \mathrm{cm}^{2}\right)$. The integrated QCM sensitivity $\left(C_{f}\right)$ is $2.013 \mathrm{~Hz} / \mathrm{ng}$ for a $9 \mathrm{MHz}$ crystal. AuNPs on the IgY coating on the chip increased the frequency from 104 to 179 $\mathrm{Hz}$ and the surface coverage of IgY from $3.1 \times 10^{-12}$ to $5.4 \times$ $10^{-12} \mathrm{~mol} / \mathrm{cm}^{2}(\sim 1.7$ times$)$. These results reveal that the gold nanoparticles increased the IgY binding capacity. This finding was consistent with a study in which the deposition of AuNPs on an electrode in an electrochemical biosensor substantially increased the sensitivity of the biosensor to arsenite. ${ }^{43}$ Other assays that are based on the use of nanotubes as a medium for detecting target molecules also provided amplified assay signals. ${ }^{44-46}$ Hence, this work also demonstrated that adding AuNPs to a QCM chip provided additional spaces for the immobilization of antibodies, increasing the change in frequency of the assay.

Optimization of Assay Time by Controlling Flow Rate of the QCM System. The flow rate and the duration of interaction of molecules with the sensor system critically affect the sensitivity of a flow injection mode sensor system. ${ }^{47,48}$ Accordingly, an attempt was made herein to reduce the time required to analyze $2 \mathrm{ppm}$ gliadin while retaining the sensitivity of the assay by optimizing the flow rate through the AuNPmodified chip (Figure 4A). According to Figure 4B, when the flow rate was maintained at $60 \mu \mathrm{L} / \mathrm{min}$, although the assay could be completed in $10 \mathrm{~min}$, the frequency only slightly changed. Setting the flow rate at a lower value increased the change in frequency, perhaps by increasing the contact time in which IgY could interact with the gliadin. However, completing an assay at a lower flow rate took longer. According to the inset figure, the optimal detection flow rate in this assay was $10 \mu \mathrm{L} /$ min, which yielded the largest change in frequency, $108 \mathrm{~Hz}$, with an assay time of about $40 \mathrm{~min}$.

Repeatability of the Detection of Gliadin by QCM Biosensor. A detection platform must be stable and ensure that any experiment in which it is used can be repeated or reproduced accurately. Hence, the repeatability of the developed QCM assay must be evaluated. The repeatability is the variability of the measurements that were obtained using inter-AuNP-modified chips. According to Figure 5A, the five runs of the analysis of the negative control (60\% ethanol) in an 


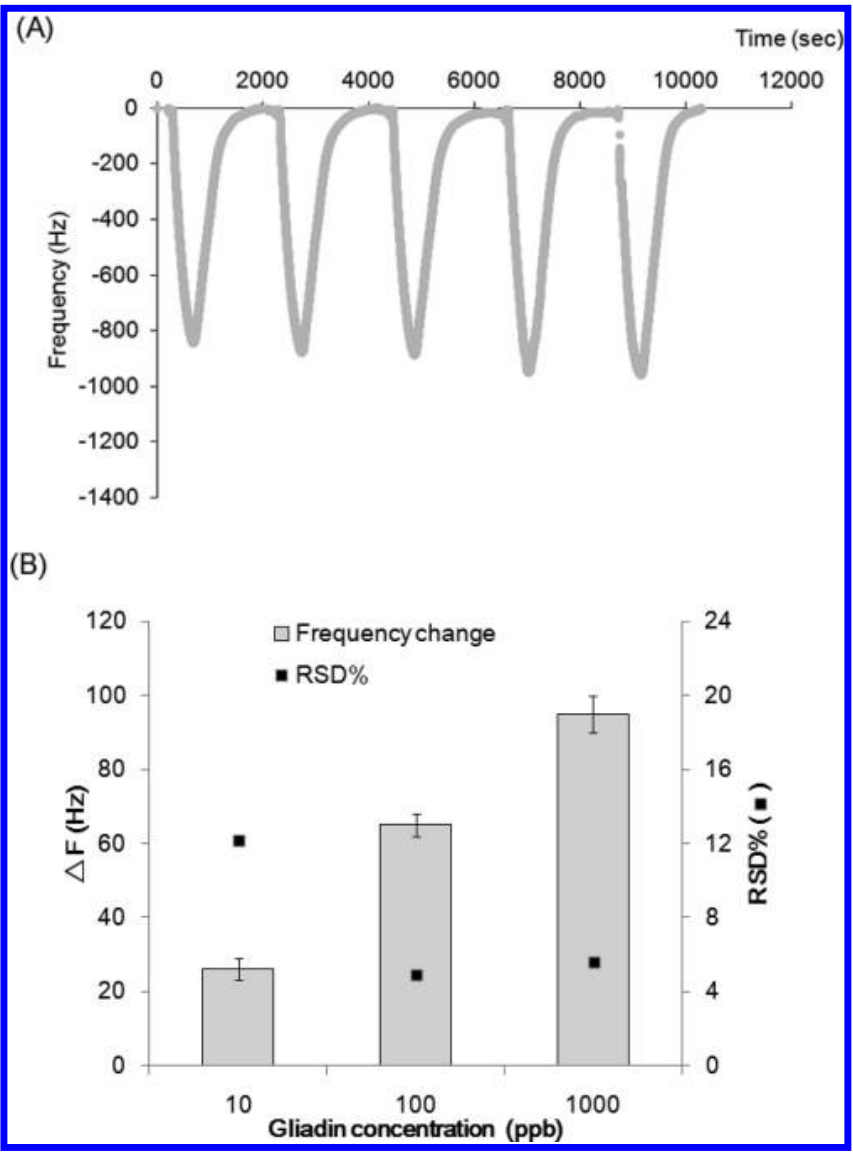

Figure 5. (A) Repeatability of nonstop analysis of negative control (60\% ethanol) using a AuNP-modified chip. Three concentrations of gliadin $(10,100$, and $1000 \mathrm{ppb})$ were continually analyzed in an AuNP-modified chip, and this procedure was repeated in triplicate using three individual chips. (B) The change in frequency and RSD associated with each gliadin concentration were calculated.

AuNP-modified QCM chip revealed no variation in the baseline among the runs, indicating that the $\operatorname{IgY}$ molecules that were coated on the AuNP-modified chip were very stably immobilized. Furthermore, 10, 100, and $1000 \mathrm{ppb}$ gliadin were continually analyzed in an AuNP-modified chip, and this procedure was repeated in triplicate using three individual chips. Figure $5 \mathrm{~B}$ displays the results thus obtained. The mean $\Delta F$ was determined to be $26 \pm 3,65 \pm 3$, and $95 \pm 5 \mathrm{~Hz}$ for 10 , 100 , and $1000 \mathrm{ppb}$ gliadin, respectively. The reliability was calculated using the relative standard deviation (\%RSD), which was $12.2,4.9$, and $5.6 \%$ with 10,100 , and $1000 \mathrm{ppb}$ gliadin, respectively. All of the RSD values in this test were $<15 \%$, indicating the feasibility of this developed immunosensor. ${ }^{49}$ These findings demonstrate that the proposed QCM with the AuNP-modified chip provides consistent and satisfactory analytical results with respect to gliadin.

Assay Sensitivity. The sensitivity of the proposed method was evaluated on the basis of the detection of gliadin at various concentrations $\left(1 \times 10^{1}-2 \times 10^{5} \mathrm{ppb}\right)$ in $60 \%$ ethanol. The limit of detection (LOD) and the limit of quantitation (LOQ) of this assay were determined from the dose-response curve (Figure 6). The LOD and LOQ were defined as the least concentration of analytes that could be distinguished from the background signal by 3 and 10 standard deviations of the baseline noise, respectively. ${ }^{50}$ The $R^{2}$ values of the doseresponse curves of bare and AuNP-modified QCM chips were 0.953 and 0.997; the LOQ values were 26 and $11 \mathrm{ppb}$, and the LOD values were estimated to be 22 and $8 \mathrm{ppb}$, separately. The slope of the standard curve represented the sensitivity of the assay, and the AuNP-modified chip was associated with a greater value (39.584 vs 30.113). Therefore, the AuNPmodified chip was utilized in the final assay in this study.

Numerous methods for detecting gliadin have been reported. Three ELISAs using anti-gliadin monoclonal antibodies had different LOD values, $3.2 \mathrm{ppm}$ for R5-ELISA, ${ }^{51} \geq 150 \mathrm{ppm}$ for AOAC-ELISA, ${ }^{52}$ and $1.5 \mathrm{ppm}$ for a sandwich ELISA using two monoclonal antibodies. ${ }^{53}$ The LOD of a nonimmune assay in the detection of gliadin using a microfluorimeter was 4.1 ppm; ${ }^{54}$ that of a fluorescence correlation spectroscopy assay was $60 \mathrm{ppb}$ gliadin. ${ }^{55}$ The use of the AuNP-modified chip gave this QCM biosensor a low LOD of $8 \mathrm{ppb}$ in detecting gliadin and, so, improved protection against accidental contamination of gliadin-free food products by gluten.

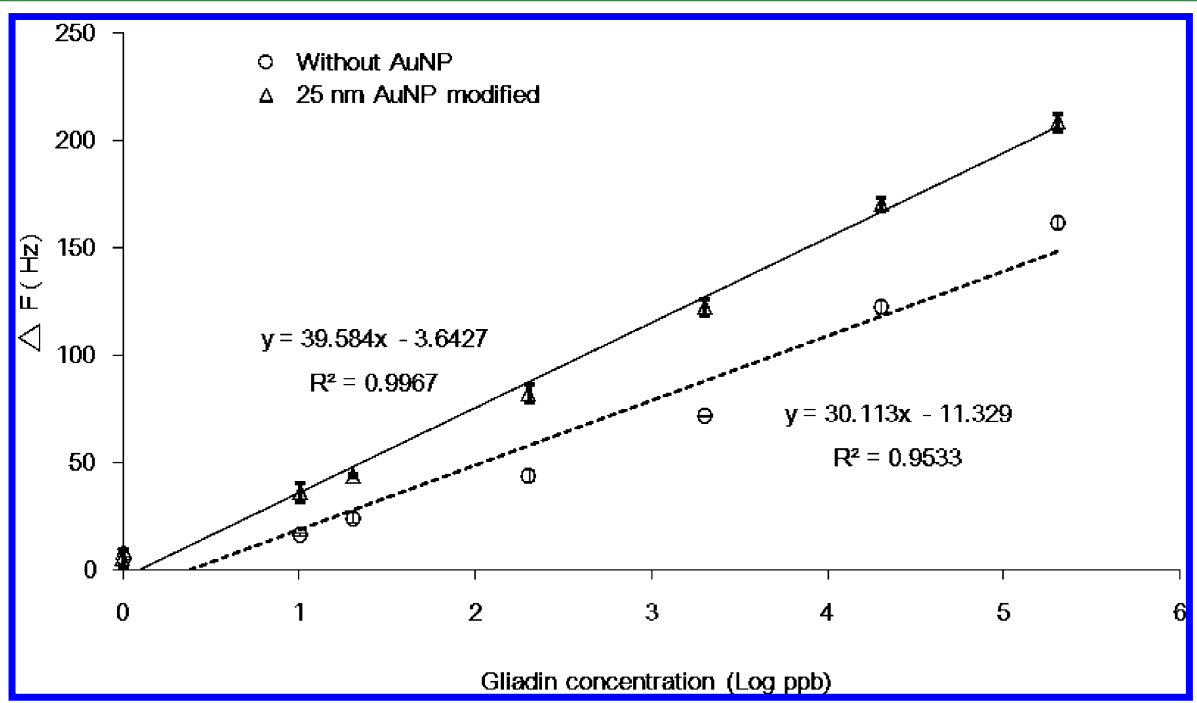

Figure 6. Two dose-response curves of gliadin in 60\% ethanol. Solid and dotted lines are regression lines obtained using the developed QCM with the AuNP-modified chip or the bare chip, respectively. LOD of the bare chip was calculated to be $22 \mathrm{ppb}$ gliadin, and $R^{2}$ was 0.953 . LOD of the AuNP-modified chip was calculated to be $8 \mathrm{ppb}$ gliadin, and $R^{2}$ was 0.997 . 


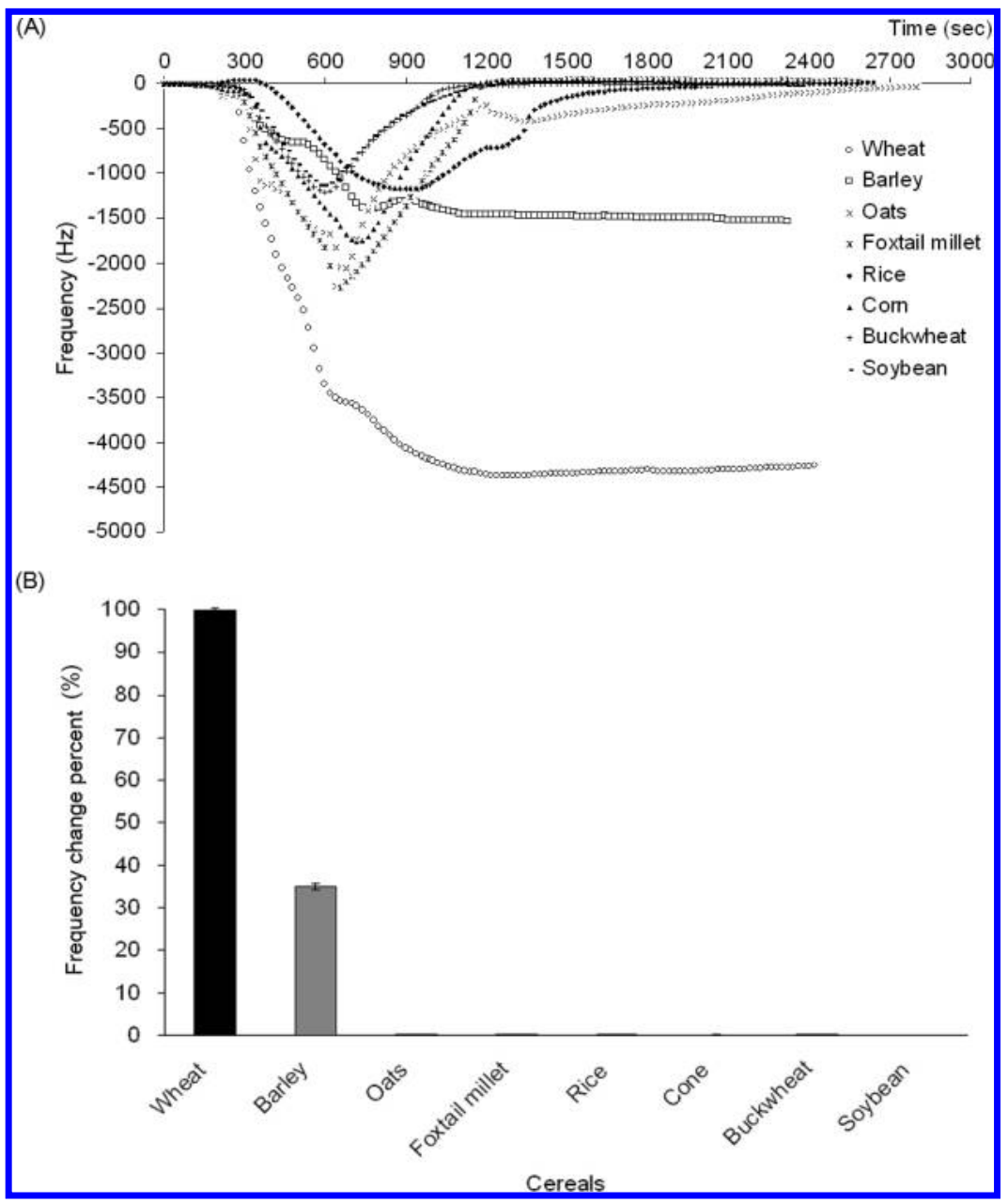

Figure 7. Specificity of the developed QCM assay: (A) variation in frequency of alcohol-soluble proteins from 5 g samples of eight common cereals; (B) percentage change in frequency of alcohol-soluble proteins of eight common cereals relative to that of wheat.

Practical Applications of QCM Biosensor in Real Food Samples. Because the anti-gliadin antibodies from the yolk that was used in the assay developed herein were polyclonal, the specificity of this assay must be evaluated. Most related works have tried to identify gliadin-free food by quantifying the gliadin in a test sample. ${ }^{15,53}$ Therefore, in this work, eight cereal samples were processed to remove the water-soluble albumins and salt-soluble globulins before extraction with $60 \%$ ethanol to obtain gliadin in samples. ${ }^{56-58}$ Figure 7 summarizes the results of the QCM assays of cereals that underwent extraction using $60 \%$ ethanol. Besides wheat, only barley showed a significant frequency change among the other seven cereals (Figure 7A). With the percentage change in frequency $(\Delta F \%)$ in the detection of gliadin in wheat defined as $100 \%$, that in the detection of barley was 35\% (Figure 7B). This cross-reactivity might have been caused by the binding of polyclonal antigliadin IgY antibodies to structurally similar epitopes in barley, which are homologous with those in wheat or contain sequences identical or nearly identical to those in wheat. Hence, the cross-reactivity between wheat and barley can be explained with reference to taxonomic relationships among various species of the same family that have strong protein sequence similarities. ${ }^{59,60}$ On average, the results concerning the specificity of this developed assay are satisfactory for the other considered cereals, which are oat, foxtail, millet, rice, corn, buckwheat, and soybean.
The recovery rate reflected the efficiency of extraction of gliadin upon measurement following the addition of a known amount of gliadin to a real food sample. Gliadin-free spaghetti in tomato sauce was spiked with gliadin $(1-1000 \mathrm{ppm})$ to determine its rate of recovery. Figure 8 summarizes the results concerning the recovery rate. When $1 \mathrm{ppm}$ gliadin was added, a

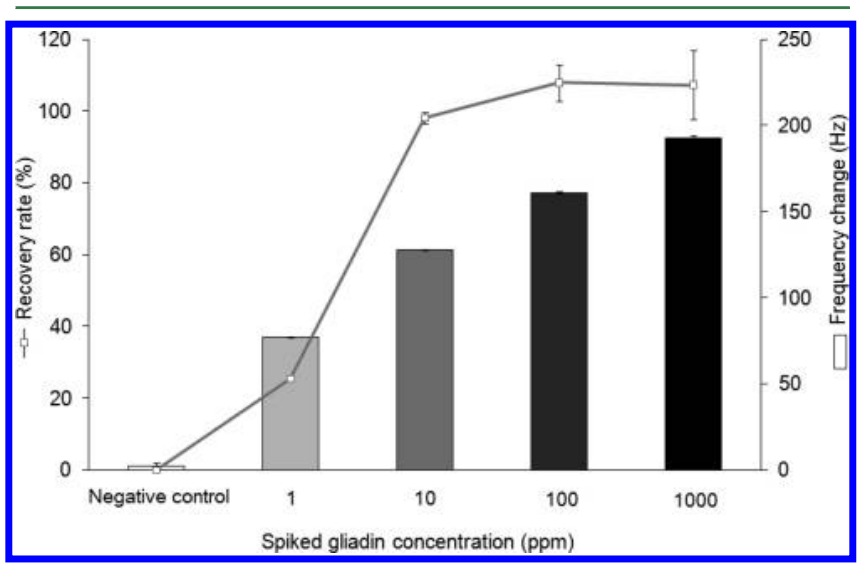

Figure 8. Recovery rate and frequency change of spiked gliadin in a gliadin-free food sample. Various concentrations of gliadin (1-1000 ppm) were spiked into gliadin-free spaghetti in tomato sauce, extracted, and then measured by the developed QCM assay. 
low recovery rate $(25 \%)$ was obtained. However, when $10-$ $1000 \mathrm{ppm}$ gliadin was added, the recovery rates were close to $100 \%$ (98-107\%). The direct approach to detect gliadin in food is effective from 1 to $1000 \mathrm{ppm}$ of gliadin $\left(R^{2}=0.996\right)$ with the detection limit as $1 \mathrm{ppm}$ of gliadin. The results indicate that the combination of this extraction method with the developed QCM assay using the AuNPs-modified chip can be used for detecting gliadin in food samples, because its detection limit is lower than the official limit of gluten-free foods that has been set by the European Commission of 20 ppm of gluten, which equals $10 \mathrm{ppm}$ of gliadin. In addition, the minimum detectable concentration of gliadin in the food matrix using this developed QCM assay exceeded that in the buffer environment, perhaps because of disturbance of the sample matrix by fat, carbohydrate, and other entities, probably blocking the antibody binding sites and then affecting the antibody-antigen interaction. ${ }^{61}$ These factors may have affected the performance of the assay, reducing its sensitivity. Table 2 presents the

Table 2. Specificity and Sensitivity of QCM in Detection of Gliadin at Three Levels of Contamination in a Foodstuff (Buckwheat)

\begin{tabular}{lccccc} 
& \multicolumn{3}{c}{ predicted group } & & \\
\cline { 2 - 4 } actual group & $\begin{array}{c}\text { gliadin- } \\
\text { free }\end{array}$ & $\begin{array}{c}\text { low-gliadin } \\
\text { content }\end{array}$ & $\begin{array}{c}\text { gliadin- } \\
\text { containing }\end{array}$ & total & $\begin{array}{c}\text { sensitivity } \\
(\%)\end{array}$ \\
$\begin{array}{l}\text { gliadin-free } \\
\text { low-gliadin } \\
\text { content }\end{array}$ & 7 & 2 & 0 & 9 & 78 \\
$\begin{array}{c}\text { gliadin- } \\
\text { containing }\end{array}$ & 0 & 6 & 3 & 9 & 67 \\
total & 7 & 0 & 9 & 9 & 100 \\
specificity (\%) & 100 & 75 & 12 & 27 & \\
& & & 75 & &
\end{tabular}

sensitivity and specificity of the three gliadin contamination levels in a single foodstuff (buckwheat). "Gliadin-free", "lowgliadin", and "gliadin-containing" refer to gliadin concentrations in the foodstuff of $<10,10-100$, and $>100 \mathrm{ppm}$, respectively. The false-negative rate in the low-gliadin and gliadin-containing food samples and the false-positive rate in the gliadin-free sample were 0 and $22 \%$, respectively.

Products for gluten-free diets are becoming more available globally. In food factories with poor quality control, crosscontamination with wheat may be serious. Therefore, detecting wheat contamination is the top priority for manufacturers of gluten-free food products. To test the feasibility of the developed QCM assay in the detection of real food samples, 10 commercial products were used. Table 3 summarizes the gliadin concentrations in 10 commercial products that were determined using either the developed QCM assay or a commercial ELISA kit that is approved by AOAC. This commercial kit is used to detect gliadin using monoclonal antibodies that recognize the peptide QQPFP. ${ }^{19}$ In Table 3, the first 4 of the 10 food samples were certified gluten-free by the Spanish Federation of Celiac Association, whereas the others containing wheat had allergen information concerning wheat at their packaging. The results of the tests herein reveal that the AuNP-modified chip can be used to detect gliadin in food samples because no false-negative result was obtained. Comparing the gliadin concentrations determined using the two methods revealed no significant difference for any of the tested samples. The gluten-free baby rice food product contained a higher concentration of gluten than the other three gluten-free products, but the concentration did not
Table 3. Concentration of Gliadin in Food Samples Determined Using either the Developed QCM Assay or a Commercial ELISA Kit Approved by AOAC

\begin{tabular}{lcc} 
& \multicolumn{2}{c}{ gliadin conctration $(\mathrm{ppm})$} \\
\cline { 2 - 3 } food sample & QCM & RIDASCREEN Gliadin \\
gluten-free products $^{a}$ & & \\
pancake mix & $0.6 \pm 0.0$ & $0.6 \pm 0.0$ \\
custard mix & $0.9 \pm 0.1$ & $0.6 \pm 0.0$ \\
baby rice & $8.3 \pm 0.8$ & $7.6 \pm 0.1$ \\
buckwheat & $0.7 \pm 0.1$ & $0.7 \pm 0.1$ \\
wheat-containment products & & \\
rye biscuit & $41.0 \pm 1.8$ & $35.6 \pm 1.3$ \\
digestive biscuit & $55.4 \pm 4.8$ & $43.2 \pm 0.9$ \\
plain crackers & $53.2 \pm 0.4$ & $41.6 \pm 0.9$ \\
red date wheat crispy biscuit & $32.2 \pm 3.4$ & $29.0 \pm 1.0$ \\
cream cracker & $30.8 \pm 2.0$ & $27.0 \pm 0.3$ \\
crisp flakes of rice and wheat & $44.2 \pm 2.8$ & $38.3 \pm 1.3$
\end{tabular}

${ }^{a}$ The gluten-free products had the quality label of "Controlado por FACE", which guaranteed that the products are safe for consumption by persons with celiac disease by the Spanish Federation of Celiac Associations.

exceed the legal limit. For all wheat-containing products, QCM measured a higher average gliadin content than the ELISA kit did. The results in Figure 1 indicate that the 60\% ethanol extraction method in the QCM assay yielded more $\omega$-gliadin than RIDA extraction in the commercial ELISA kit did, resulting in more gliadin molecules at which the anti-gliadin IgY could bind. The polyclonal anti-gliadin IgY that was used in the QCM assay also provided a higher intensity of the signal than the monoclonal antibody in the commercial ELISA kit did, because polyclonal antibodies can bind to more than one epitope per antigen, whereas monoclonal antibodies can bind to only one epitope per antigen. ${ }^{62}$ Accordingly, the different anti-gliadin antibodies (polyclonal vs monoclonal) in these two assays might react with different quantities of gliadin, resulting in slightly different assay results. In Table 4, the sensitivity and

Table 4. Contingency Matrix Obtained from the Change of Frequency Measured Using QCM for Ethanolic Extracts from 30 Samples of 10 Foodstuffs (4 "Gluten-Free" and 6 "Gluten-Containing") Confirmed by an AOAC Approved ELISA kit

\begin{tabular}{lcccc} 
& \multicolumn{2}{c}{ predicted group } & & \\
\cline { 2 - 3 } \multicolumn{1}{c}{ actual group } & $\begin{array}{c}\text { gluten- } \\
\text { free }\end{array}$ & $\begin{array}{c}\text { gluten- } \\
\text { containing }\end{array}$ & total & $\begin{array}{c}\text { sensitivity } \\
(\%)\end{array}$ \\
$\begin{array}{l}\text { gluten-free food samples } \\
\text { gluten-containing food }\end{array}$ & 12 & 0 & 12 & 100 \\
$\quad$ samples & 0 & 18 & 18 & 100 \\
total & 12 & 18 & 30 & 100 \\
specificity (\%) & 100 & 100 & 100 & \\
\hline
\end{tabular}

specificity of the QCM for 30 samples of the 10 foodstuffs (4 gluten-free and 6 that contain wheat) were both $100 \%$. Therefore, the developed QCM biosensor was suited to identify gliadin contamination in food. It will therefore be valuable in the manufacture of gluten-free foods and help ensure compliance with international standards for gluten-free food.

Conclusion. In this work, a novel, rapid, and sensitive method for detecting gliadin in gliadin-free food using a QCM 
biosensor was developed. AuNPs are assembled on a gold electrode in the sensor to detect gliadin. This proposed chip modification increases by $48 \%$ the shift in the frequency of the QCM immunosensor in the detection of $2 \mathrm{ppm}$ gliadin. The developed QCM immunosensor had a high sensitivity with a detection limit of $8 \mathrm{ppb}$ gliadin in $60 \%$ ethanol. It can be practically utilized for food samples with a detection limit of 1 ppm gliadin. The difference between the LOD of gliadin in 60\% ethanol and in food samples may be an effect of the food matrix, because some food compounds, such as lipids or carbohydrates, may interrupt the antibody-antigen interaction, reducing the sensitivity of the assay. ${ }^{63}$ The total analysis time was around $40 \mathrm{~min}$, and analyses of gliadin were highly repeatable, with stable results. The developed immunosensor may help food manufacturers to label accurately their gliadincontaining products and may help protect consumers who have allergies to gliadin. Additional research must be performed to improve the AuNP density in the QCM chip.

\section{AUTHOR INFORMATION}

\section{Corresponding Author}

* Postal address: Department of Food Science and Biotechnology, National Chung Hsing University, 250 Kuo Kuang Road, Taichung 402, Taiwan, ROC. Phone: +886-4-22840385, ext. 5020. Fax: +886-4-22876211. E-mail: hwwen@nchu.edu.tw.

\section{Funding}

We thank the National Science Council of the Republic of China, Taiwan, for financially supporting this research under Contract NSC 98-2313-B-005-037-MY3.

\section{Notes}

The authors declare no competing financial interest.

\section{ACKNOWLEDGMENTS}

Ted Knoy is appreciated for his editorial assistance.

\section{REFERENCES}

(1) Bock, S. A.; Atkins, F. M. Patterns of food hypersensitivity during sixteen years of double blind, placebo-controlled food challenges. $J$. Pediatr. 1990, 117, 561-567.

(2) Rancé, F.; Kanny, G.; Dutau, G.; Moneret-Vautrin, D. A. Aspects cliniques de l'allergie alimentaire. Rev. Fr. Allergol. 1998, 38, 900-905.

(3) Sicherer, S. H. Determinants of systemic manifestations of food allergy. J. Allergy. Clin. Immunol. 2000, 106, S251-257.

(4) Imai, T.; Iikura, Y. The national survey of immediate type of food allergy. Arerugi 2003, 52, 1006-1013.

(5) Huang, C. F. The prevalence of allergic diseases in primary school in $y u$-li and the common allergens in Eastern Taiwan. Thesis, Institute of Biomedical Sciences, National Sun Yat-sen Theses, 2005.

(6) Dupont, F. M.; Altenbach, S. B. Molecular and biochemical impacts of environmental factors on wheat grain development and protein synthesis. J. Cereal Sci. 2003, 38, 133-146.

(7) Palosuo, K.; Alenius, H.; Varjonen, E.; Koivuluhta, M.; Mikkola, J.; Keskinen, H.; Kalkkinen, N.; Reunala, T. A novel wheat gliadin as a cause of exercise-induced anaphylaxis. J. Allergy. Clin. Immunol. 1999, 103, 912-917.

(8) Sollid, L. M. Coeliac disease: dissecting a complex inflammatory disorder. Nat. Rev. Immunol. 2002, 2, 647-655.

(9) Walker-Smith, J. A.; Guandalini, S.; Schmitz, J.; Shmerling, D. H.; Visakorpi, J. K. Revised criteria for diagnosis of coeliac disease. Report of working group of European society of paediatric gastroenterology and nutrition. Arch. Dis. Child. 1990, 65, 909-911.

(10) Hischenhuber, C.; Crevel, R.; Jarry, B.; Mäki, M.; MoneretVautrin, D. A.; Romano, A.; Troncone, R.; Ward, R. Review article: safe amounts of gluten for patients with wheat allergy or coeliac disease. Aliment. Pharmacol. Ther. 2006, 23, 559-575.
(11) Stern, M.; Ciclitira, P. J.; van Eckert, R.; Feighery, C.; Janssen, F. W.; Méndez, E.; Mothes, T.; Troncone, R.; Wieser, H. Analysis and clinical effects of gluten in coeliac disease. Eur. J. Gastroenterol. Hepatol. 2001, 13, 741-747.

(12) Commission regulation (EC) No 41/2009 of 20 January 2009 concerning the composition and labelling of foodstuffs suitable for people intolerant to gluten. Off. J. Eur. Union 2009, 52, 3-5.

(13) Camafeita, E.; Alfonso, P.; Mothes, T.; Méndez, E. Matrixassisted laser desorption/ionization time-of-flight mass spectrometric micro-analysis: the first non-immunological alternative attempt to quantify gluten gliadins in food samples. J. Mass. Spectrom. 1997, 32, 940-947.

(14) Köppel, E.; Stadler, M.; Lüthy, J.; Hübner, P. Detection of wheat contamination in oats by polymerase chain reaction (PCR) and enzyme-linked immunosorbent assay (ELISA). Z. Lebensm. Unters. Forsch. 1998, 206, 399-403.

(15) Zeltner, D.; Glomb, M. A.; Maede, D. Real-time PCR systems for the detection of the gluten-containing cereals wheat, spelt, kamut, rye, barley and oat. Eur. Food Res. Technol. 2009, 228, 321-330.

(16) Simonato, B.; Mainente, F.; Tolin, S.; Pasini, G. Immunochemical and mass spectrometry detection of residual proteins in gluten fined red wine. J. Agric. Food Chem. 2011, 59, 3101-3110.

(17) Nassef, H. M.; Bermudo Redondo, M. C.; Ciclitira, P. J.; Ellis, H. J.; Fragoso, A.; O'Sullivan, C. K. Electrochemical immunosensor for detection of celiac disease toxic gliadin in foodstuff. Anal. Chem. 2008, 80, 9265-9271.

(18) Skerritt, J. H.; Hill, A. S. Monoclonal antibody sandwich enzyme immunoassays for determination of gluten in foods. J. Agric. Food Chem. 1990, 38, 1771-1778.

(19) De Stefano, L.; Rossi, M.; Staiano, M.; Mamone, G.; Parracino, A.; Rotiroti, L.; Rendina, I.; Rossi, M.; D’Auria, S. Glutamine-binding protein from Escherichia coli specifically binds a wheat gliadin peptide allowing the design of a new porous silicon-based optical biosensor. $J$. Proteome Res. 2006, 5, 1241-1245.

(20) Peres, A. M.; Dias, L. G.; Veloso, A. C.; Meirinho, S. G.; Sá Morais, J.; Machado, A. A. S. C. An electronic tongue for gliadins semiquantitative detection in foodstuffs. Talanta 2011, 83, 857-864.

(21) Thompson, T.; Méndez, E. Commercial assays to assess gluten content of gluten-free foods: why they are not created equal. J. Am. Diet. Assoc. 2008, 108, 1682-1687.

(22) Pollet, J.; Delport, F.; Janssen, K. P.; Tran, D. T.; Wouters, J.; Verbiest, T.; Lammertyn, J. Fast and accurate peanut allergen detection with nanobead enhanced optical fiber SPR biosensor. Talanta 2010, 83, 1436-1441.

(23) Sauerbrey, G. Verwendung von Schwingquarzen zur Wägung dünner Schichten und zur Mikrowägung. Z. Phys. 1959, 155, 206-222. (24) Hao, R.; Wang, D.; Zhang, X.; Zuo, G.; Wei, H.; Yang, R.; Zhang, Z.; Cheng, Z.; Guo, Y.; Cui, Z.; Zhou, Y. Rapid detection of Bacillus anthracis using monoclonal antibody functionalized QCM sensor. Biosens. Bioelectron. 2009, 24, 1330-1335.

(25) Tang, D. P.; Yuan, R; Chai, Y. Q.; An, H. Z. Core-shell magnetic $\mathrm{CoFe}_{2} \mathrm{O}_{4} / \mathrm{SiO}_{2}$ composite nanoparticles as immobilized affinity supports for clinical immunoassay. Adv. Funct. Mater. 2007, 17, 976-982.

(26) March, C.; Manclús, J. J.; Jiménez, Y.; Arnau, A.; Montoya, A. A piezoelectric immunosensor for the determination of pesticide residues and metabolites in fruit juices. Talanta 2009, 78, 827-833.

(27) Su, X. L.; Li, Y. A QCM immunosensor for Salmonella detection with simultaneous measurements of resonant frequency and motional resistance. Biosens. Bioelectron. 2005, 21, 840-848.

(28) Hong, S. R.; Choi, S. J.; Jeong, H. D.; Hong, S. Development of QCM biosensor to detect a marine derived pathogenic bacteria Edwardsiella tarda using a novel immobilisation method. Biosens. Bioelectron. 2009, 24, 1635-1640.

(29) Kurosawa, S.; Park, J. W.; Aizawa, H.; Wakida, S. I.; Tao, H.; Ishihara, K. Quartz crystal microbalance immunosensors for environmental monitoring. Biosens. Bioelectron. 2006, 22, 473-481.

(30) Hirst, E. R.; Yuan, Y. J.; Xu, W. L.; Bronlund, J. E. Bondrupture immunosensors - a review. Biosens. Bioelectron. 2008, 23, 1759-1768. 
(31) Zhao, W.; Brook, M. A.; Li, Y. F. Design of gold nanoparticlebased colorimetric biosensing assays. Chem. Bio. Chem. 2008, 9, 23632371.

(32) Pingarrón, J. M.; Yáñez-Sedeño, P.; González-Cortés, A. Gold nanoparticle-based electrochemical biosensors. Electrochim. Acta 2008, $53,5848-5866$

(33) Li, S. H.; Xia, Y. T.; Zhang, J. P.; Han, J. H.; Jiang, L. Polystyrene spheres coated with gold nanoparticles for detection of DNA. Electrophoresis 2010, 31, 3090-3096.

(34) Chen, S. H.; Chuang, Y. C.; Lu, Y. C.; Lin, H. C.; Yang, Y. L.; Lin, C. S. A method of layer-by-layer gold nanoparticles hybridization in a quartz crystal microbalance DNA sensing system used to detect dengue virus. Nanotechnology 2009, 20, 1-10.

(35) Kim, W. K.; Patterson, P. H. Production of an egg yolk antibody specific to microbial uricase and its inhibitory effects on uricase activity. Poult. Sci. 2003, 82, 1554-1558.

(36) Ntakarutimana, V.; Demedts, P.; Sande, M. V.; Scharpe, S. A simple and economical strategy for downstream processing of specific antibodies to human transferrin from egg yolk. J. Immunol. Methods 1992, 153, 133-140.

(37) Polson, A.; Coetzer, T.; Kruger, J.; von Maltzahn, E.; van der Merwe, K. J. Improvements in the isolation of IgY from the yolks of eggs laid by immunized hens. Immunol. Invest. 1985, 14, 323-327.

(38) Akita, E. M.; Nakai, S. Immunoglobulins from egg yolk: isolation and purification. J. Food. Sci. 1992, 57, 629-634.

(39) Saraiva, S. M.; de Oliveira, J. F. Control of particle size in the preparation of colloidal gold. J. Disper. Sci. Technol. 2002, 23, 837-844.

(40) Wieser, H. Chemistry of gluten proteins. Food Microbiol. 2007, 24, 115-119.

(41) Schlecht, U.; Malavé, A.; Gronewold, T.; Tewes, M.; Löhndorf, M. Comparison of antibody and aptamer receptors for the specific detection of thrombin with a nanometer gap-sized impedance biosensor. Anal. Chim. Acta 2006, 573-574, 65-68.

(42) Migneault, I.; Dartiguenave, C.; Bertr, M. J.; Waldron, K. C. Glutaraldehyde: behavior in aqueous solution, reaction with proteins, and application to enzyme crosslinking. Biotechniques 2004, 37, 798802.

(43) Majid, E.; Hrapovic, S.; Liu, Y.; Male, K. B.; Luong, J. H. T. Electrochemical determination of arsenite using a gold nanoparticle modified glassy carbon electrode and flow analysis. Anal. Chem. 2006, $78,762-769$.

(44) Chang, H. X.; Yuan, Y.; Shi, N. L.; Guan, Y. F. Electrochemical DNA biosensor based on conducting polyaniline nanotube array. Anal. Chem. 2007, 79, 5111-5115.

(45) Luo, X. L.; Killard, A. J.; Smyth, M. R. Nanocomposite and nanoporous polyaniline conducting polymers exhibit enhanced catalysis of nitrite reduction. Chem.-Eur. J. 2007, 13, 2138-2143.

(46) Kim, M.; Kim, M. J. Isocitrate analysis using a potentiomentric biosensor with immobilised enzyme in a FIA system. Food Res. Int. 2003, 36, 223-230.

(47) Feng, Y.; Yang, T.; Zhang, W.; Jiang, C.; Jiao, K. Enhanced sensitivity for deoxyribonucleic acid electrochemical impedance sensor: gold nanoparticle/polyaniline nanotube membranes. Anal. Chim. Acta 2008, 616, 144-151.

(48) Oota, S.; Hatae, Y.; Amada, K.; Koya, H.; Kawakami, M. Development of mediated BOD biosensor system of flow injection mode for shochu distillery wastewater. Biosens. Bioelectron. 2010, 26, $262-266$.

(49) Venosa, A. D.; King, D. W.; Sorial, G. A. The baffled flask test for dispersant effectiveness: a round robin evaluation of reproducibility and repeatability. Spill. Sci. Technol. Bull. 2002, 7, 299-308.

(50) Plata, M. R.; Hernando, J.; Zougagh, M.; Contento, A. M.; Villaseñor, M. J.; Sánchez-Rojas, J. L.; Ríos, A. Characterization and analytical validation of a microcantilever-based sensor for the determination of total carbonate in soil samples. Sens. Actuators. B: Chem. 2008, 134, 245-251.

(51) Valdés, I.; García, E.; Llorente, M.; Méndez, E. Innovative approach to low-level gluten determination in foods using a novel sandwich enzyme-linked immunosorbent assay protocol. Eur. J. Gaastroenterol. Hepatol. 2003, 15, 465-474.

(52) ELISA Technologies. Committed to food and feed safety. ELISA Technologies Web site, http://www.elisa-tek.com (accessed April 2, 2012).

(53) Sorell, L.; Lopez, J. A.; Valdes, I.; Alfonso, P.; Camafeita, E.; Acevedo, B.; Chirdo, F. G.; Gavilondo, J.; Méndez, E. An innovative sandwich ELISA system based on an antibody cocktail for gluten analysis. FEBS. Letts. 1998, 439, 46-50.

(54) Mairal, T.; Frese, I.; Llaudet, E.; Bermudo Redondo, C. B.; Katakis, I.; von Germar, F.; Drese, K.; O’Sullivan, C. K. Microfluorimeter with disposable polymer chip for detection of coeliac disease toxic gliadin. Lab. Chip. 2009, 9, 3535-3542.

(55) Varriale, A.; Rossi, M.; Staiano, M.; Terpetschnig, E.; Barbieri, B.; Rossi, M.; D'Auria, S. Fluorescence correlation spectroscopy assay for gliadin in food. Anal. Chem. 2007, 79, 4687-4689.

(56) Sánchez-Martínez, M. L.; Aguilar-Caballos, M. P.; Gómez-Hens, A. Homogeneous stopped-flow fluorimmunoassay for gliadin determination in food samples. Anal. Chim. Acta 2004, 523, 35-41.

(57) Van den Broeck, H. C.; America, A. H.; Smulders, M. J.; Bosch, D.; Hamer, R. J.; Gilissen, L. J.; Meer, I. M. A modified extraction protocol enables detection and quantification of celiac disease-related gluten proteins from wheat. J. Chromatogr., B: Anal. Technol. Biomed. Life Sci. 2009, 877, 975-982.

(58) Gessendorfer, B.; Koehler, P.; Wieser, H. Preparation and characterization of enzymatically hydrolyzed prolamins from wheat, rye, and barley as references for the immunochemical quantitation of partially hydrolyzed gluten. Anal. Bioanal. Chem. 2009, 395, 17211728 .

(59) Palosuo, K.; Alenius, H.; Varjonen, E.; Kalkkinen, N.; Reunala, $\mathrm{T}$. Rye gamma- 70 and gamma-35 secalins and barley gamma- 3 hordein cross-react with omega-5 gliadin, a major allergen in wheat-dependent, exercise-induced anaphylaxis. Clin. Exp. Allergy 2001, 31, 466-473.

(60) Breiteneder, H.; Radauer, C. A classification of plant food allergens. J. Allergy. Clin. Immunol. 2004, 113, 821-830.

(61) Chunglok, W.; Wuragil, D. K.; Oaew, S.; Somasundrum, M.; Surareungchai, W. Immunoassay based on carbon nanotubesenhanced ELISA for Salmonella enterica serovar Typhimurium. Biosens. Bioelectron. 2011, 26, 3584-3589.

(62) Lipman, N. S.; Jackson, L. R.; Trudel, L. J.; Weis-Garcia, F. Monoclonal versus polyclonal antibodies: distinguishing characteristics, applications, and information resources. ILAR J. 2005, 46, 258268.

(63) Zhang, H.; Wang, L.; Zhang, Y.; Fang, G.; Zheng, W.; Wang, S. Development of an enzyme-linked immunosorbent assay for seven sulfonamide residues and investigation of matrix effects from different food samples. J. Agric. Food Chem. 2007, 55, 2079-2084. 